\title{
COMPARISON OF A CYCLIC BEHAVIOR OF 316L STEEL IN UNIAXIAL AND MULTIAXIAL CYCLIC LOADING
}

\author{
L. Poczklán*, V. Mazánová**, T. Kruml ${ }^{* * *}$
}

\begin{abstract}
A study of the cyclic behavior of austenitic stainless steel 316L was carried out in uniaxial loading, pure torsional loading and multiaxial in phase loading. Experiments were performed on hollow cylindrical specimens with polished surface. The specimens were cyclically loaded at room temperature with constant total strain amplitude. The specimen surface was observed by scanning electron microscopy and the microstructure was investigated by transmission electron microscopy. Differences in the mechanical response in different loading modes are discussed. It was found that the exhibited secondary hardening is caused by both the phase transformation and the appearance of $\alpha$ martensite. The phase transformation is more intense in the case of torsional loading as compared to axial loading. The crack initiation mechanism does not change considerably in individual modes. Persistent slip bands occur and fatigue cracks initiate along them.
\end{abstract}

Keywords: fatigue behavior, multiaxial cyclic loading, phase transformation, 316L stainless steel, fatigue crack initiation

\section{Introduction}

Austenitic stainless steel 316L is widely used in many structural applications given its excellent corrosion resistance and good mechanical properties at temperatures up to $700{ }^{\circ} \mathrm{C}$. Since numerous structural components are cyclically loaded, it is necessary to know the cyclic response of the material. Most of the components are loaded by combined forces whereas most of the fatigue studies are dealing with uniaxial loading.

Considering the industrial importance of $316 \mathrm{~L}$ steel, its fatigue properties have been studied frequently (e.g. Gerland et al., 1989, Vogt et al., 1991 and Li et al., 1994). Most of the works were focused on the mechanical response in uniaxial fatigue. Studies of damaging mechanisms in multiaxial fatigue are rare. Moreover, 316L steel is a material rich on deformation mechanisms which are strongly affected by its chemical composition. A planar dislocation glide is regularly observed, but when a stacking fault energy (SFE) is higher, cross-slip of dislocation leading to an evolution of a low energy 3D dislocation structures appears (Obrtlík et al., 1994). A deformation twinning can appear more easily if the SFE is low. Laths of hexagonal $\varepsilon$ martensite were also mentioned in the literature (Kruml et al., 2000). Finally, formation of tetragonal $\alpha$ martensite could appear. A standard for the chemical composition of $316 \mathrm{~L}$ allows rather large variation of an element content; e.g. an amount of $\mathrm{Ni}$ is 10-14 wt. \%. Therefore, there can be differences in deformation mechanisms among 316L steels with different chemical compositions.

\section{Material and methods}

Experimental material was supplied by Acerinox Europa in a form of hot rolled plates. The microstructure was formed by equiaxed grains of austenite with an average size of $40 \mu \mathrm{m}$ and some thin $\delta$ ferrite bands.

\footnotetext{
* Ing. Ladislav Poczklán.: Institute of Physics of Materials; Žižkova 22; 616 62, Brno; CZ, poczklan@ipm.cz

** Ing. Veronika Mazánová: Institute of Physics of Materials; Žižkova 22; 616 62, Brno; CZ, mazanova@ipm.cZ

*** prof. Mgr. Tomáš Kruml, CSc.: CEITEC IPM; Žižkova 22; 616 62, Brno; CZ, kruml@ipm.cz
} 
The mechanical properties given by supplier are: $\mathrm{R}_{\mathrm{p} 0,2}=336 \mathrm{MPa}, \mathrm{R}_{\mathrm{m}}=586 \mathrm{MPa}$ and $\mathrm{A}=57 \%$. Its chemical composition is given by Tab. 1 .

Tab. 1: The chemical composition of the austenitic steel 316L in wt. \%

\begin{tabular}{llllllllll}
\hline $\mathrm{C}$ & $\mathrm{Cr}$ & $\mathrm{Mn}$ & $\mathrm{Mo}$ & $\mathrm{N}$ & $\mathrm{Ni}$ & $\mathrm{P}$ & $\mathrm{S}$ & $\mathrm{Si}$ & $\mathrm{Fe}$ \\
\hline 0.018 & 16.631 & 1.261 & 2.044 & 0.042 & 10.000 & 0.032 & 0.001 & 0.380 & bal. \\
\hline
\end{tabular}

Tubular cylindrical specimens were machined from the plates without any following heat treatment. The gauge part of the specimens was $28 \mathrm{~mm}$ in length, $12 \mathrm{~mm}$ in the external diameter and $2 \mathrm{~mm}$ of the thickness of the wall. The inner hole was fabricated by spark erosion. The external surface of the gauge part was subsequently mechanically and electrolytically polished for reaching a smooth surface suitable for planned observations. Mechanical loading was done at room temperature on a computer controlled MTS 809 servohydraulic machine. All tests were done in a symmetrical cycling; $\left(R_{\varepsilon}=-1\right)$ with constant total strain amplitude. A plastic strain amplitude was determined as a half-width of a hysteresis loop in the middle of the fatigue life. The strain rate was $3 \times 10^{-3} \mathrm{~s}^{-1}$, considering the low thermal conductivity of the material. An equivalent strain and an equivalent stress were calculated using Eq. 1 and Eq. 2 respectively.

$$
\begin{aligned}
& \varepsilon_{\mathrm{eq}}=\sqrt{\varepsilon^{2}+\gamma^{2} / 3} \\
& \sigma_{\mathrm{eq}}=\sqrt{\sigma^{2}+3 \tau^{2}}
\end{aligned}
$$

The specimens were observed in a Field Emission Gun Scanning Electron Microscope (FEGSEM) Tescan Lyra 3 and in a Transmission Electron Microscope (TEM) JEOL 2100F. Thin plates for a TEM foil preparation were cut from the bulk specimen by an electric-discharge machine. TEM foils were prepared by the electrolytic polishing.

\section{Results and discussion}

\subsection{Mechanical response}

Cyclic hardening/softening curves obtained from the cycling in three different modes with the same total equivalent strain amplitude $\varepsilon_{\text {eq,tot }}=0.44 \%$ are shown in Fig. 1 . The ratio between the axial and the torsional strain in the case of multiaxial loading was $\varepsilon /\left(\frac{\gamma}{\sqrt{3}}\right)=1$. The mechanical response is similar for all three cycling regimes. An initial hardening caused by the increasing dislocation density is followed by a cyclic softening due to the localization of the cyclic plastic deformation which results in a formation and a growing of persistent slip bands (PSB). After approximately 4000 cycles (about $25 \%$ of the fatigue life), the secondary cyclic hardening appears in all three modes. The striking feature is the intensity of the secondary hardening in torsion, which is much more pronounced than the hardening in other modes. The curve representing axial loading lies above the curve representing multiaxial loading; however, the difference between these two curves is relatively small (less than $2 \%$ of absolute value).

Fig. 2 shows cyclic stress-strain curves in equivalent values of the stress and the plastic strain, taken at a half-life. While the curve representing torsional loading lies clearly above the two other curves, the axial and multiaxial curves overlap within the experimental scatter typical for fatigue testing (Schijve, 2009). The reason is the strong hardening in torsional loading which affects values in the half-life. Fatigue life $\mathrm{S} / \mathrm{N}$ curves, which relate fatigue life to the equivalent stress amplitude at the half-life, show a similar trend and are plotted in Fig. 3. Once again, a similar trend is observed in axial and multiaxial loading while the specimens cycled in pure torsion have a longer fatigue life.

\subsection{Fatigue crack initiation}

Initiation sites of fatigue cracks in uniaxial and multiaxial loading modes are shown in Figs. 4 and 5. In all three loading modes, persistent slip bands develop and surface bands with extrusions and intrusions are formed. It is evident from Figs. 4 and 5 that fatigue cracks initiate from PSBs and grow along them. This finding is in agreement with studies of Fatemi et al. (2011) and Polák et al. (2014). 


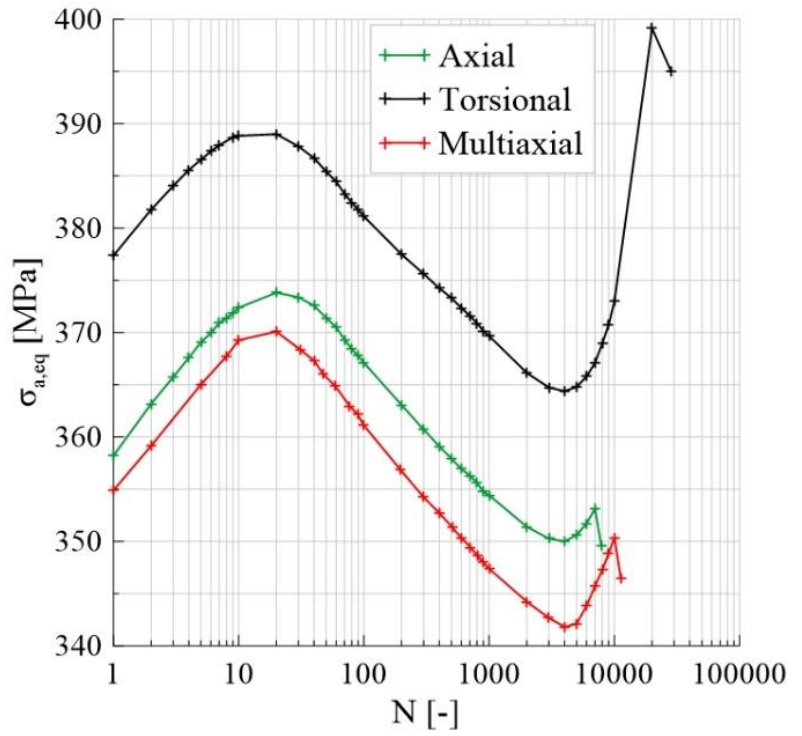

Fig. 1. Cyclic hardening/softening curves of three different cycling modes with the same total equivalent strain amplitude.

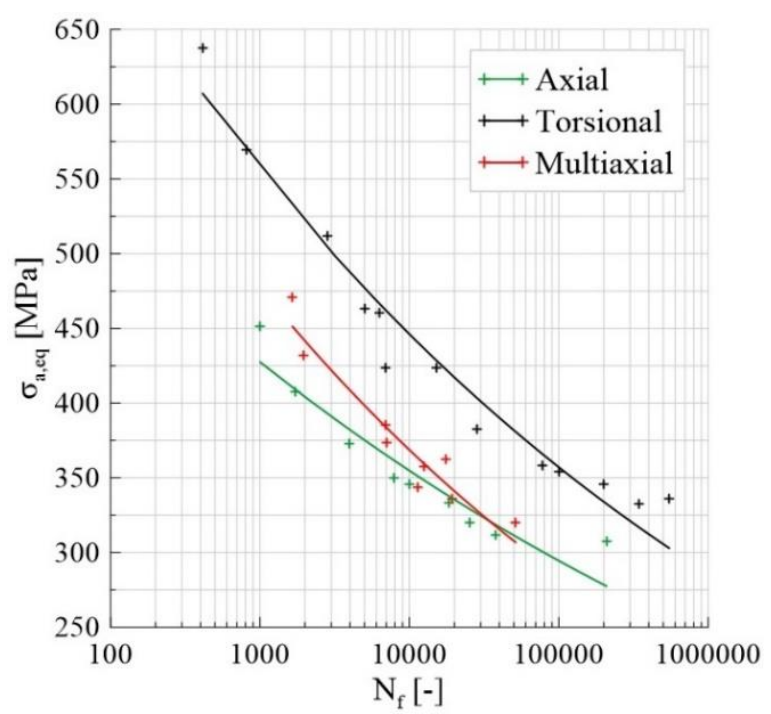

Fig. 3. S/N curves.

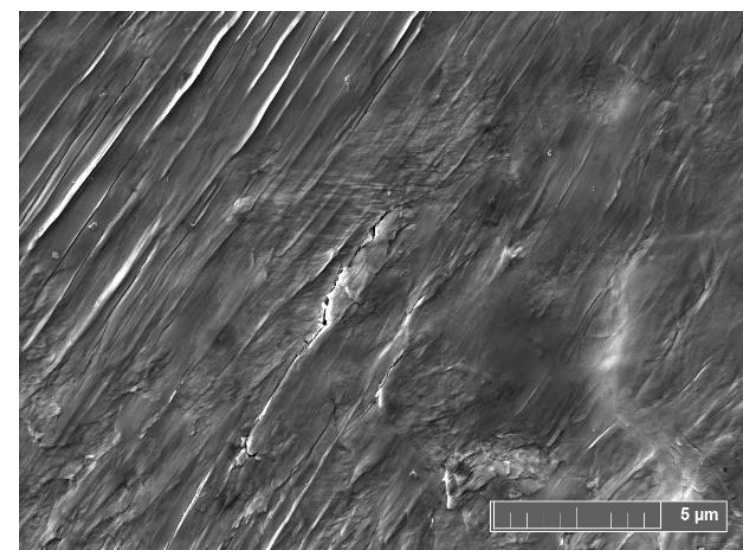

Fig. 5. The fatigue crack initiation in multiaxial cycling.

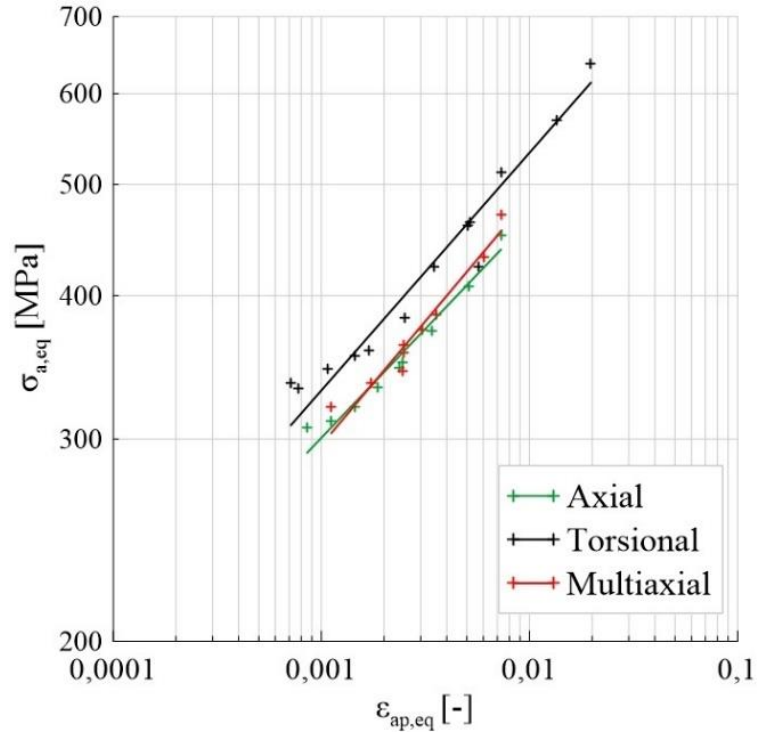

Fig. 2. Cyclic stress-strain curves.

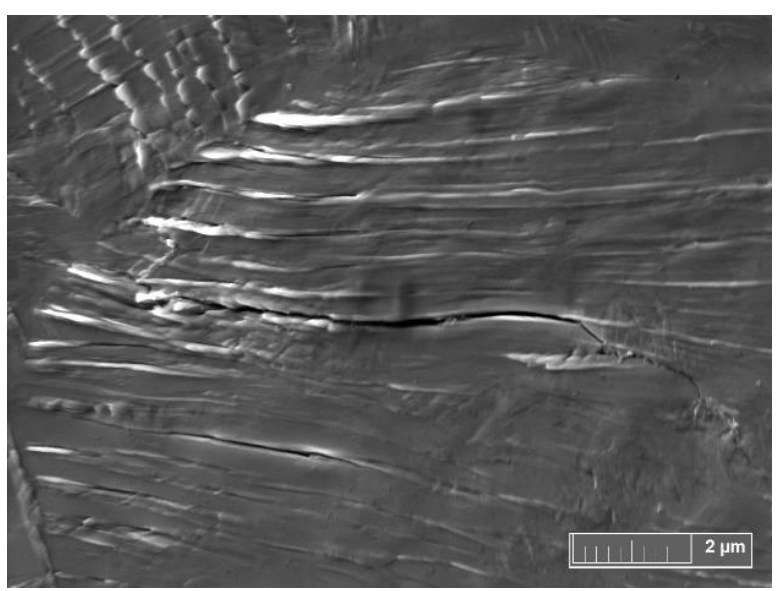

Fig. 4. The fatigue crack initiation in uniaxial cycling.

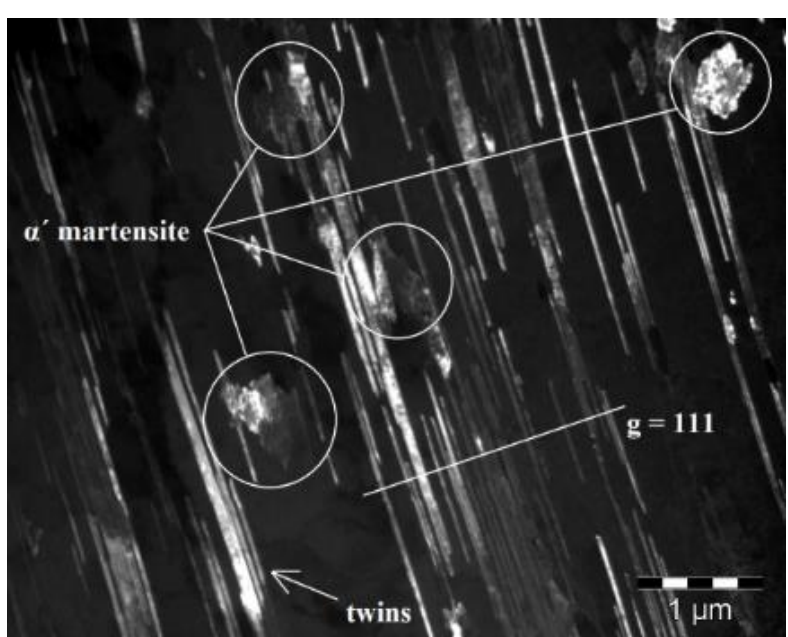

Fig. 6. Micrograph of an austenitic matrix (dark), mechanical twins (thin lamellae) and $\alpha$ 'martensite islands in TEM dark field imaging. 


\subsection{Microstructural changes during cycling}

It was found by TEM analysis that in cycling, the microstructure is changed in three aspects: i) a dislocation substructure evolve: the dislocation density increases and characteristic 3D dislocation arrangements are formed (Obrtlík et al. 1994), ii) a formation of deformation microtwins, iii) $\alpha$ martensite islands appear (Fig. 6). Martensite is a magnetic phase; therefore its presence and a quantity can be measured by a magnetic measurement. Preliminary results both of TEM analyses and of magnetic measurement indicate that the phase transformation from austenite to martensite is much more intense in pure torsion than in two other loading modes. This observation is in agreement with Hong et al. (2007) who argued that this transformation is easier in conditions of shear stress. Rapid formation of $\alpha$ martensite is the cause of strong secondary cyclic hardening in torsion and probably also of an increase of fatigue life.

\section{Conclusions}

The most important findings of this work are the following:

- Secondary cyclic hardening of 316L steel is substantially higher in the case of pure torsional loading in comparison with other two modes. This loading mode exhibits a longer fatigue life.

- Fatigue cracks initiate along PSBs in all three modes.

- Dislocations are rearranged during the cycling, deformation twins are formed and finally, the phase transformation $\gamma \rightarrow \alpha^{\prime}$ occurs.

\section{Acknowledgement}

This research has been financially supported by The Ministry of Education, Youth and Sports of the Czech Republic under the project "Architectured Materials Designed for Additive Manufacturing" CZ.02.1.01/0.0/0.0/16_025/0007304 and by The Grant Agency of the Czech republic No. 18-03615S.

\section{References}

Fatemi, A. and Shamsaei, N. (2011) Multiaxial fatigue: An overview and some approximation models for life estimation. International Journal of Fatigue, 33, pp. 948-958.

Gerland, M., Mendez, J., Violan, P., Saadi, B. (1989) Evolution of Dislocation-Structures and Cyclic Behavior of a 3161-Type Austenitic Stainless-Steel Cycled Invacuo at Room-Temperature. Materials Science and Engineering A, 118, pp. 83-95.

Hong, S.G., Lee, S.B., Byun, T.S. (2007) Temperature effect on the low-cycle fatigue behavior of type 316L stainless steel: Cyclic non-stabilization and invariable fatigue parameter. Materials Science and Engineering A, 457, pp. 139-147.

Kruml, T., Polák, J., Degallaix, S. (2000) Microstructure in 316LN stainless steel fatigued at low temperature. Materials Science and Engineering A, 293, pp. 275-280.

Li, Y. and Laird, C. (1994) Cyclic Response and Dislocation Structures of AISI 316L Stainless-Steel. Part 2: Polycrystals Fatigued at Intermediate Strain Amplitude. Materials Science and Engineering A, 186, pp. 87-103.

Obrtlík, K., Kruml, T., Polák, J. (1994) Dislocation-Structures in 3161 Stainless-Steel Cycled with Plastic Strain Amplitudes Over a Wide Interval. Materials Science and Engineering A, 187, pp. 1-9.

Polák, J. and Man, J. (2014) Mechanisms of extrusion and intrusion formation in fatigued crystalline materials. Materials Science and Engineering A, 596, pp. 15-24.

Schijve, J. (2009) Fatigue of structures and materials. Springer, Dordrecht.

Vogt, J.B., Foct, J., Regnard, C., Robert, G., Dhers, J. (1991) Low-Temperature Fatigue of 316L and 316LN Austenitic Stainless Steels. Metallurgical Transactions A, 22, pp. 2385-2392. 